\title{
Evaluation of an inpatient preventive treatment program for soldiers returning from deployment
}

\author{
Peter Zimmermann ${ }^{\mathrm{a}, *}$, Jens Kowalski ${ }^{\mathrm{a}}$, Angelika Niggemeier-Groben ${ }^{\mathrm{a}}$, Melanie Sauer ${ }^{\mathrm{a}}$, \\ Robert Leonhardt ${ }^{\mathrm{a}}$ and Andreas Ströhle ${ }^{\mathrm{b}}$ \\ ${ }^{a}$ German Armed Forces Centre of Military Mental Health, Bundeswehr Hospital Berlin, Berlin, Germany \\ ${ }^{\mathrm{b}}$ Charité University Hospital, Clinic of Psychiatry and Psychotherapy, Berlin, Germany
}

\begin{abstract}
.
BACKGROUND: Since 1999, the German Armed Forces (Bundeswehr) have been conducting 3-weeks preventive treatment programs aimed at psychological resource-strengthening in soldiers returning from deployment.

METHODS: Five hundred participants of these programs received the Posttraumatic Stress Scale 10 (PTSS-10) before and after treatment and the rehabilitation assessment questionnaire of the German statutory pension insurance body. Sixty control group subjects received the PTSS-10 twice in an interval of 4-5 months without therapeutic interventions.

RESULTS: Comparison of pre- and post-treatment PTSS-10 results in the covariance analysis showed an effect of the initial PTSS-10-stress-levels and rank category, not of the intervention.

On average, the treatment program received 'very good' to 'excellent' overall ratings in the rehabilitation questionnaire. The acceptance of sports and movement therapy was significantly above average, whereas that of individual and group counselling was below.

CONCLUSIONS: The results of this pilot study suggest a high acceptance of the post-deployment preventive program. Effectiveness in terms of psychometric improvement cannot be proven at this point.
\end{abstract}

Keywords: Deployment, German Armed Forces, prevention, soldiers, treatment

\section{Introduction}

Since the first military mission of the German Armed Forces (Bundeswehr) with a field hospital in Cambodia in 1992-1993, over 300,000 Bundeswehr soldiers have been deployed to war and conflict zones. Operations abroad subject soldiers and their families to considerable levels of stress. Accordingly, recent epidemiological surveys have shown an increase in the prevalence and incidence rates of various psychiatric

*Address for correspondence: Peter Zimmermann, Bundeswehrkrankenhaus/Abt. 6B, Scharnhorststr.13, 10115 Berlin, Germany. Tel.: +49 3028411600; Fax: +49 3028411603; E-mail: peter1zimmermann@bundeswehr.org. illnesses among soldiers returning from deployment, in particular of posttraumatic stress disorder (PTSD) [1].

At the same time, the number of service members being treated for psycho-reactive disorders in the psychiatric clinics of Bundeswehr hospitals has risen significantly over the past years ci2,3. Comparable developments have been observed in other armed forces [4].

Against this background, the importance of strategies to prevent mental disorders before and after military deployments (primary and secondary prevention) has increased in recent years [5] In terms of content throughout other armed forces, these therapeutic measures e.g. have aimed at reinforcing physical fitness, humour, hope, group cohesion within military units, social support, a sense of purpose, spirituality, and optimism [6]. 
As early as 1999, in addition to former short-term programs [7], the Bundeswehr began cooperating with civilian contracting clinics in establishing 3-weeks inpatient restorative treatment programs including a limited offer of counselling, but no traumatherapeutic approaches. The aim of these activities was to give soldiers suffering from deployment-related stress but did not yet display symptoms of mental illness an opportunity for psycho-physical regeneration and a strengthening of resources in order to improve spontaneous regeneration processes and prevent the development of psychiatric disorders [8]. This additional preventive element was promoted by former critics of soldiers and also by the German public that Bundeswehr soldiers would not receive adequate psychological care after deployment.

Outside the military, inpatient psychotherapeutic programs are common for various purposes in German rehabilitation treatment facilities, including 3-weeks cure treatments or 6-weeks intensive multimodal psychotherapy for various psychiatric disorders. Rehabilitation is a frequently used supplement to acute psychiatric clinics in Germany. Since 1997, the German pension scheme (Deutsche Rentenversicherung Bund) has been using standardised patient questionnaires to evaluate the subjective success of rehabilitation, to compare facilities, and thus to aid in the establishment of generally applicable benchmarks.

With regard to the Bundeswehr, a preventive inpatient treatment program of one civilian contracting clinic was evaluated $[9,10]$. In the course of this evaluation, numerous psychometric tests were conducted on a small sample that revealed an improvement of psychological stress-levels among rehabilitants in the follow-up history. The evaluated subjects were, however, selected according to the severity of the stress they had experienced, there was no control group, and a differentiated evaluation of the individual treatments was not possible.

The aim of the present pilot study therefore was to evaluate the severity of perceived psychological distress among subjects in several contracting clinics based on the PTSS-10 before and after a course of treatment and subsequently to evaluate satisfaction with the entire treatment as well as with individual measures. This approach might support hypotheses regarding the effects of such treatments in the secondary prevention of deployment-related distress in soldiers, but also in other professional groups who must cope with similar levels of stress.

\section{Material and methods}

\subsection{Procedures}

The participants of this study were selected based on data provided by the Bundeswehr central approving authority for civil rehabilitation treatment (Bundeswehr Medical Office, Munich). Five hundred soldiers were included who had completed their course of treatment at least 3 months before the survey. In order to guarantee sufficient experience with treatment procedures and with military personnel, clinics had to have treated at least 7 soldiers per year before. Eleven German facilities qualified. In order to apply for the treatment program, the soldiers had been required to hand in an up-to-date PTSS-10 test along with the application form. Initial testing was therefore fully documented.

Code numbers were then allocated and the questionnaire of the German pension scheme (for description, see below) was sent out along with a second PTSS10 test, a covering letter, and a declaration of consent regarding the collection of personal data for the purposes of the study. A self-addressed, stamped envelope was included. The documents were not sent out a second time. Two hundred subjects filled out the questionnaires (response rate 40\%). The collected data was sent to the Centre of Military Mental Health in Berlin where an anonymised evaluation was conducted.

\subsection{Subjects and application}

Table 1 shows the demographic and military data of the 200 subjects in the treatment group and of the 60 members of the control group.

The requirements for a preventive treatment program, its course, and the application procedure are governed by a ministerial directive [8]. In detail, the directive specifies the following indications long periods of separation from home; assignments of 2 months or more in combination with a 7-day working week; high levels of stress during daytime duty; lack of personal space; confrontation with another culture, violence and poverty; unfamiliar climate; extreme events (attacks, shelling, combat, threats, accidents, etc.) [8].

Applications must be filed within 6 months after the end of deployment, either by the soldiers, their superior officers, or a Bundeswehr psychosocial counsellor and sent in via the unit physician, who will take a general medical history and conduct a PTSS-10 test beforehand [11]. A psychiatrist opinion is not re- 
Table 1

Sample characteristics (Branch: branch of service; Combat: combat force; ComS: combat support force; Med: medical corps; Days: total days on deployment; MV: Mean Value)

\begin{tabular}{|c|c|c|c|c|}
\hline \multicolumn{4}{|l|}{ Parameters } & \multirow{2}{*}{$\begin{array}{l}\text { Significance } \\
\text { Chi-squared test }\end{array}$} \\
\hline Gender & Male & Female & & \\
\hline Treatment group & $\mathrm{N}=177(88.5 \%)$ & $\mathrm{N}=23(11.5 \%)$ & & Chi-squared $(1)=3.542$ \\
\hline Control group & $\mathrm{N}=58$ & $\mathrm{~N}=2$ & & $p=0.060$ \\
\hline Rank & Enlisted personnel & NCOs & Officers & Chi-squared test \\
\hline Treatment group & $\mathrm{N}=17(8.5 \%)$ & $\mathrm{N}=130(65.3 \%)$ & $\mathrm{N}=52(26.1 \%)$ & Chi-squared (2) $=35.22$ \\
\hline Control group & $\mathrm{N}=24(40 \%)$ & $\mathrm{N}=29(48.3 \%)$ & $\mathrm{N}=7(11.7 \%)$ & $p<0.001$ \\
\hline Branch & Combat & ComS & Med & \\
\hline (only treatment group) & $\mathrm{N}=48(25 \%)$ & $\mathrm{N}=106(55.2 \%)$ & $\mathrm{N}=38(19.8 \%)$ & \\
\hline Age & & & & Mann-Whitney U test \\
\hline Treatment group & MV 35.9 (SD 8.81) & & & $\mathrm{Z}=5.350$ \\
\hline Control group & MV 29.3 (SD 6.01) & & & $p<0.001$ \\
\hline Days & & & & Mann-Whitney U test \\
\hline Treatment group & MV 339 (SD 249.9) & & & $Z=1.894$ \\
\hline Control group & MV 262 (SD 184.1) & & & $p=0.058$ \\
\hline
\end{tabular}

quired. Soldiers who fail to provide evidence of stress as well as those who display symptoms of a manifest deployment-related psychiatric disorder or obtain results of $>35$ points in the PTSS-10 (suspected PTSD) are ineligible for the preventive treatment program. In the latter case, psychiatric treatment at a Bundeswehr hospital will be arranged.

\subsection{Services offered during treatment programs}

Preventive treatment programs are a free-of-charge, voluntary, inpatient rehabilitative measure for soldiers, reservists, and civilian Bundeswehr employees. Treatment takes place in civilian clinics contracted by the Bundeswehr. The Bundeswehr currently maintains 27 contracts with facilities throughout Germany. The Bundeswehr Medical Office in Munich selects the clinic, although the applicant may state priorities, which are usually taken into consideration. Relatives may also be admitted, but must pay a daily rate for board and accommodation.

Contracted institutions must provide the following services:

- Medical examination upon admission

- Various sporting and leisure facilities catering to different patient needs regarding physical condition and personal inclination (nordic walking, water gym exercises, running, hiking)

- Physiotherapy (muscle strengthening, pain management, massage)

- Courses in various relaxation techniques (progressive muscle relaxation, breathing and imagination techniques)
- Ergotherapy (painting and handcrafts for improving emotional expression)

- Individual and group counselling (management of individual resources, improvement of social contacts, general stress and conflict management)

- Medical support

Clinics have a certain degree of flexibility regarding the form and administration of treatments, however. Traumatherapy or specific psychotherapy is not part of the contracts because of the shortness of time and the limited financial flexibility. These approaches are offered by German Armed Forces Hospitals.

\subsection{Data collection tools}

The Posttraumatic Stress Scale 10 (PTSS-10) had shown satisfactory psychometric properties in former studies [11] and was chosen for this evaluation because it has been in use as a screening tool in the Bundeswehr since the mid-1990s and unit physicians employ it for routine primary care screening for deployment-related psychological and posttraumatic stress.

The PTSS-10 was employed along with the questionnaire for quality assurance in psychosomatic hospitals prepared by the German pension scheme providers (Handbuch zur Rehabilitandenbefragung DRV, 2010, unpublished data). The questionnaire was slightly modified for the purposes of this study (besides biographical data, basic military data was also collected). The following questions were analysed in the course of this study:

1. "How do you rate the success of the preventive treatment program and the treatment program as a whole?" (5-step scale from 'poor' (1) to 'excel- 
Table 2

PTSS-10 results (raw values) of treatment group and control group before and after course of treatment/waiting interval

\begin{tabular}{llrccc}
\hline Variable & Group & $\mathrm{N}$ & Mean Value (MV) & Standard Deviation (SD) & Mann-Whitney U test \\
\hline PTSS-10 before treatment & Treatment group & 198 & 20.32 & 7.907 & $\mathrm{Z}=4.423$ \\
& Control group & 59 & 15.84 & 7.164 & $p<0.001$ \\
PTSS-10 after treatment & Treatment group & 192 & 18.83 & 7.394 & $\mathrm{Z}=1.594$ \\
& Control group & 59 & 17.34 & 7.246 & $p=0.111$ \\
Difference & Treatment group & 191 & -1.49 & 8.373 & $\mathrm{Z}=2.319$ \\
& Control group & 58 & 1.50 & 5.868 & $p=0.020$ \\
\hline
\end{tabular}

lent' (5) and from 'very poor' (1) to 'very good' (5))

2. "Did you receive the following treatments? If so, how do you rate them?" (Subjects "No, I did not" or "Yes, and I rate it...". The negative answer was not considered further in the evaluation, otherwise a differentiated rating of the services listed in Table 5 was offered on a 5-step scale from 'very poor' (1) to 'very good' (5)).

The patients' assessment of the individual measures received during the program was analysed on the basis of these questions. The average score in all categories and the deviation of single categories from this average were determined.

For comparison purposes, a control-group $(n=60)$ was set up. Soldiers of a Bundeswehr unit returning from deployment who had filled in a post-deployment questionnaire including the PTSS-10 were asked by their unit physician to complete the test again after 45 months, thus representing a comparable interval as the main group. Only soldiers who had not undergone a preventive treatment program were admitted. Upon submission of the PTSS-10, the subjects were asked to sign a declaration of consent regarding the analysis of their anonymised data.

\subsection{Statistics}

The target value for the evaluation of the PTSS-10 was the sum score before and after treatment and the difference (posttest score minus pretest score), including only patients with complete data sets. According to the Kolmogorov-Smirnov test, the data was not normally distributed. The aim of the survey was to establish whether the development of the sum scores of the treatment group was significantly different (better) than that of the control group. This was tested in an initial step by means of the Mann-Whitney-U-test.

In a second step, variables with a potential influence on the difference were considered. These parameters were age, days on deployment, participation in counselling during the inpatient treatment (yes/no) and ini-
Table 3

Results of the covariance analysis regarding factors of influence on change of PTSS-10 sum score (difference between final and initial data) (group: treatment group or control group)

\begin{tabular}{lcc}
\hline Characteristic & $\mathrm{F}$ & $\mathrm{P}$ \\
\hline Group & 0.030 & 0.862 \\
Participation counselling & 0.034 & 0.827 \\
Gender & 0.032 & 0.858 \\
Rank category & 3.165 & $\mathbf{0 . 0 4 4}$ \\
Age & 0.097 & 0.756 \\
Days on deployment & 0.483 & 0.488 \\
Initial PTSS-10 & 101.01 & $<\mathbf{0 . 0 0 1}$ \\
\hline
\end{tabular}

Table 4

Overall assessment of treatment by participants $(1=$ poor, $5=\mathrm{ex}$ cellent) (overall success: subjective assessment of general treatment outcome; assessment of course: general subjective evaluation of the therapeutic measures)

\begin{tabular}{lccc}
\hline Question & N & MV & SD \\
\hline Overall success of treatment & 200 & 3.67 & 1.019 \\
Overall assessment of course of treatment & 200 & 4.28 & 0.902 \\
\hline
\end{tabular}

tial PTSS-10 sum score as covariates, and gender and rank category as blocking factors. (A Chi squared evaluation of rank and gender for pre-test was done because no field was empty and the expected frequency of the women's group was 5.8.)

In order to make evaluation possible, an analysis of covariance had to be performed, which is, however, applicable only to normally distributed data. Although in this case the Kolmogorov-Smirnov test did not establish a normal distribution for the differential values, deviation was minimal ( $p=0.021)$. The application of parametric procedures such as the analysis of covariance was therefore justified with regard to the evaluation of the differential values.

In all evaluations, the target values of the rehabilitation questionnaire were the answers to individual questions expressed in integral numbers ranging from 1 to 5 or from -2 to +2 (including 0 ). As the KolmogorovSmirnov test confirmed, these scores were not normally distributed. For this reason, the Wilcoxon test for dependent samples was applied in the evaluation. After performing the Bonferroni correction for multiple testing, the significance level was reduced to 0.001 . 
Table 5

Evaluation (MV) of treatments received during treatment program; column $\mathrm{N}$ shows the number of participants who received the treatment; also: results of deviation from mean (MV) of all evaluations (+: better evaluation, - : poorer evaluation) (Mann-Whitney U test)

\begin{tabular}{lrcccc}
\hline Therapeutic measures & \multicolumn{1}{c}{$\mathrm{N}$} & $\mathrm{MV}$ & $\mathrm{SD}$ & $\mathrm{Z}$ & $\mathrm{P}$ \\
\hline Individual counselling & 102 & 3.67 & 1.028 & 5.465 & $<\mathbf{0 . 0 0 1}-$ \\
Group counselling & 78 & 3.06 & 1.049 & 7.001 & $<\mathbf{0 . 0 0 1}-$ \\
Physiotherapy/training & 178 & 4.42 & 0.652 & 6.201 & $<\mathbf{0 . 0 0 1}+$ \\
Sports/movement therapy & 199 & 4.48 & 0.626 & 8.554 & $<\mathbf{0 . 0 0 1}+$ \\
Physiotherapy/massage & 197 & 4.19 & 0.990 & 1.723 & 0.085 \\
Ergotherapy & 50 & 4.36 & 0.598 & 0.813 & 0.416 \\
Expressive therapy & 29 & 4.17 & 0.759 & 1.126 & 0.260 \\
Relaxation therapy & 172 & 4.03 & 0.908 & 2.101 & 0.036 \\
\hline
\end{tabular}

A further point of evaluation was whether the parameters of age, gender, rank category, branch of service, and days on deployment had any influence on the results. This was answered with a covariance analysis using age and days on deployment as covariates and gender, rank category, and branch of service (combat forces/combat support forces/medical corps) as fixed factors. Since the target values were not normally distributed, the reliability of the results is limited.

Statistical analyses were conducted with the aid of SPSS-16 software.

\section{Results}

The initial PTSS-10 sum score of the treatment group was significantly higher than that of the control group. After the course of treatment, the difference was no longer significant (Table 2). The difference between mean values before and after treatment varied significantly in the two groups, indicating an improvement in the treatment group and a deterioration in the control group (Mann-Whitney $\mathrm{U}$ test: $Z=2.319, p=0.02$ ) (Table 2).

However, in the analysis of covariance only the initial PTSS-10 score and the rank category but not the application of an intervention significantly predicted a change in PTSS-10 scores. Higher stress values in the initial PTSS-10 and higher rank categories (officers) produced lower posttest results, while posttest results among lower ranks (enlisted personnel) deteriorated (Table 3). Other factors tested showed no significant influence.

In the pension scheme questionnaire the treatment success was rated 'good' to 'very good' (maximum value) (Table 4), whereas the treatment program as a whole was rated 'very good' to 'excellent' (maximum value).
In the assessment of individual therapeutic measures of the program (Table 5), physiotherapy ("e.g. locomotor system and postural exercises, muscle building") and sports/movement therapy ("e.g. training on bicycle ergometers, exercise in the gym or outdoors") received significantly above-average ratings from 'good' to 'very good'. Psychotherapeutic individual and group counselling received significantly lower ratings of 'soso' or 'so-so to good'.

In a joint analysis of variance with all variables of subjective assessment, the results were independent of age, gender, rank category, service branch, days on deployment, and stress-levels prior to treatment at a significance-level of 0.001 (corrected for multiple testing).

\section{Discussion}

In the present pilot study, Bundeswehr soldiers who had undergone a 3-weeks preventive treatment program in a civilian facility after deployment in Afghanistan were compared with a military control group. Although the comparison of PTSS-10 scale values before and after treatment suggested a significantly more favourable course in the treatment group $(\mathrm{Z}=$ $2.319, p=0.02$ ), the analysis of covariance showed that this effect depended on the rank category of the participants and the initial severity of their level of distress and up to this point not on the intervention group they belonged to. Therefore, specific psychometric effects of the preventive treatment program on individual stress reaction or mental health cannot be substantiated on the basis of the data available. Further research will have to address these questions more detailed.

Several previous studies have shown the impact of the initial severity of symptoms on the success of therapeutic measures, a phenomenon that has been connected to both statistical effects ('regression to the mean') as well as greater levels of suffering, which may result in a higher motivation to undergo treatment [12]. An evaluation of short-term inpatient group psychotherapy in the Bundeswehr also indicated a connection between higher symptom stress and better therapeutic results [13].

Other studies have observed comparable correlations regarding the rank categories of soldiers [14]. The higher average level of education of higher ranks, but also their longer time in service, greater work experience, and deeper social integration have all been noted as intervening variables $[13,15]$. 
In addition to the PTSS-10, a Bundeswehr version of the questionnaire for quality assurance in psychosomatic rehabilitation facilities prepared by the German pension scheme providers was completed by 200 soldiers and evaluated. The aim of this survey was to provide a differentiated subjective evaluation of the course of treatment as a whole and of its individual therapeutic elements to gain some initial insights into which of them were met with a particularly high or low acceptance among soldiers.

Treatment as a whole and its subjectively perceived success was rated between 'very good' and 'excellent', thus indicating a positive acceptance among the Bundeswehr soldiers treated.

Physiotherapy and sports/movement therapy received significantly higher ratings than other elements, especially as compared with individual and group counselling, which received the lowest ratings. Apparently, measures including physical activity most effectively meet the recuperative needs of soldiers returning from deployment, more so than offers of counselling, which, accordingly, had no effect in the analysis of variance on changes in the PTSS-10 questionnaire. Due to these results the German Armed Forces are going to modify their preventive treatment programs and give sports a greater emphasis.

The factors age, number of days on deployment, gender, rank category, and service branch (combat forces/combat support forces/medical corps) exerted an influence neither on the total rating, nor on the assessment of individual measures. This suggests that the subjective assessment of the preventive treatment programs was relatively uniform among soldiers and that specific adaptions e.g. age or gender related are not neccessary.

In summary it can be assumed that the overall subjective rating of the preventive treatment program was positive and the acceptance was high. Thus, despite the fact that the psychometric effectiveness is as yet unproven, this study suggests that soldiers experience them as an element of support after deployment, which may hypothetically contribute to overall job satisfaction.

To complement the voluntary 3-weeks preventive courses of treatment, the Bundeswehr offers compulsory post-deployment briefings for all returning personnel as a further measure of secondary prevention. In the course of the first three months after deployment, all returning soldiers are brought together in groups sorted by their deployment units to attend 3day workshops where they discuss their deployment experiences in structured sessions under the guidance of trained moderators, psychologists, social workers, and pastoral counsellors [16]. So far, there has been no scientific evaluation of the post-deployment briefings.

Other armed forces do not provide systematic inpatient secondary prevention programs comparable to the 3-weeks preventive treatment in civilian clinics described here [5].

They generally offer shorter-term options in military facilities that are comparable in parts to German post-deployment briefings. The "Comprehensive Soldier Fitness (CSF)" concept has been in use by the US Army since 1996. This program combines elements of cognitive restructuring and skills training to aid soldiers and their families before, during, and after deployment by way of workshops and virtual counselling. It is used, for example, in Warrior Transition Units - military facilities specialised on preparing (mainly physically) wounded soldiers for their reintegration into service or civilian life.

Until 2009, when it became part of CSF, the virtual component was an independent program called Battlemind Training that soldiers could participate in before and after deployment. It was accompanied by educational briefs at the redeployment phase [17]. Evaluations of CSF so far have indicated a positive effect regarding the mental health of participants [18].

The US Navy uses the Combat and Operational Stress Control (COSC) project, which contains similar elements as CSF and also applies to various phases of deployment, but focuses on elements of psychoeducation [5].

The British Armed Forces gathered positive experiences with "Trauma Risk Management" (TRiM). It is a peer-delivered model of assessment which contains elements of psycho-education and is applied immediately post-exposure and also after four weeks and three months later. Evidence could be found that TRiM may be associated with increased psychological resilience and may help to reduce stigma [19].

An interesting approach of secondary prevention by work hardening applied by occupational therapists in trauma-exposed US combat soldiers was introduced by Gerardi. The author reports good success of such strategies [20].

The role of secondary prevention among German non-military forces (police, fire brigades) has increased over the past few years, for example in the form of operational debriefings and variants thereof. However, low-threshold inpatient prevention measures are not offered on a broad scale, but only in response to 
the development of actual individual signs and symptoms [21].

Accordingly, the approach to prevention outlined in this pilot study could provide impulses for the development of comparable support measures for other professions whose personnel are often exposed to similar degrees of stress in their work.

Concerning other civil occupational environments there have been encouraging studies showing that secondary preventive combinations of individual, group and organization level interventions, most often supported by psychosocial intervention brought positive and significant results with regard to work and mental health outcomes to workers [22].

\subsection{Limitations}

The present study has several methodological limitations so that it merely qualifies as a pilot study on the subject. There was a relatively low answer rate of $40 \%$, although comparable to other Bundeswehrrelated studies [13]. In some of the groups this led to a small power in the statistical analysis.

It must also be mentioned that subjects and control group were neither randomised nor matched. Randomisation would have been difficult considering that this measure is already well-known and frequently used by Bundeswehr soldiers. As a result, tendencies of aggravation, especially with regard to the severity of stress before the course of treatment, were almost unavoidable.

In addition, as the sole instrument of evaluation, the PTSS-10 provides only a limited specificity and hence a reduced diagnostic value, leading to a considerable restriction of possible conclusions regarding stressinduced symptom development and resilience factors. Especially the exact impact of the training or its components on physical or psychological health cannot be specified on the basis of the present data.

\section{Conclusion}

The present controlled pilot study was not yet able to prove a psychometric effect of an inpatient postdeployment preventive treatment program on stress reactions and mental health of Bundeswehr soldiers. Further research will have to address this question in detail.

The study did, however, provide initial indications that the program met with positive responses among the participants. Further developments in terms of content should focus on sports and movement therapy and evaluate these aspects in detail.

\section{Acknowledgements}

We would like to thank Mr PD Dr. Roland Girgensohn for the statistical analysis, Dr. Weinert and Mr. Schalt for their extensive support with data gathering, Mr. Mahnke and Ms. Neumüller for their organisational support and help in evaluating the study.

\section{References}

[1] Wittchen HU, Schönfeld S, Kirschbaum K, Thurau C, Trautmann S, Klotsche J, Höfler M, Hauffa R, Zimmermann P. Traumatic experiences and posttraumatic stress disorder in soldiers following deployment abroad - how big is the hidden problem? Dtsch Ärztebl Int. 2012; 109(35-36): 559-568.

[2] Zimmermann P, Hahne HH, Ströhle A. Psychiatrische Erkrankungen bei Bundeswehrsoldaten - Veränderungen in der Inanspruchnahme psychiatrischer Versorgungssysteme im Vergleich der Jahre 2000 und 2006 (Psychiatric illness among Bundeswehr soldiers - changes in the utilization of medical services in association with out-of-area deployments). Trauma und Gewalt. 2009; 3(4): 316-327.

[3] Kowalski JT, Hauffa R, Jacobs H, Höllmer H, Zimmermann P. Inanspruchnahme psychiatrisch-psychotherapeutischer Leistungen nach einsatzbedingten Belastungen bei Soldaten der Bundeswehr (Utilization of psychiatric-psychotherapeutic treatment resources after deployment-related stressors in Bundeswehr soldiers). Ä Dtsch Ärztebl Int. 2012; 109(35-36): 569-575.

[4] Fear NT, Jones M, Murphy D, Hull L, Iversen AC, Coker B. What are the consequences of deployment to Iraq and Afghanistan on the mental health of the UK armed forces? A cohort study. Lancet. 2010; 375: 1783-1797.

[5] Morgan BJ, Bibb SC. Assessment of military populationbased psychological resilience programs. Mil Med 2011; 176(9): 976-985.

[6] Southwick S. Adapting to stress:lessons from the resilient. Paper presented at the 2010 Navy and Marine Corps Combat Operational Stress Conference: Taking action, measuring results. May 18-21, 2010, San Diego, CA. Available from: http: //www.med.navy.mil.

[7] Bundesministerium der Verteidigung (German Armed Forces Ministry of Defence). Richtlinie für die Einsatznachbereitung im Hinblick auf Psychotraumata bei Soldaten der Bundeswehr nach Auslandseinsätzen (Guidelines for postdeployment support in Bundeswehr soldiers). Bonn: BMVgVerlag; 1996.

[8] Bundesministerium der Verteidigung (German Armed Forces Ministry of Defence). Richtlinie zu Präventivkuren (Guidelines for preventive treatments). Bonn: BMVg-Verlag; 1999.

[9] Schubmann R. Therapieprogramm zur konstruktiven TraumaBearbeitung für Soldaten nach militärischen Einsätzen (Treatment program for Bundeswehr soldiers after deployment). Wehrmed Mschr. 2001; 7: 129-133.

[10] Müller-Holthusen T. Ergebnisse eines psychosomatischen Behandlungsprogramms für Soldaten nach Extrembelastungen bei Auslandseinsätzen (Results of a psychosomatic treatment program for Bundeswehr soldiers after deployment). Wehrmed Mschr. 2007; 9: 261-268. 
[11] Raphael R, Lundin T, Weisaeth W. A research method for the study of psychological and psychiatric aspects of disaster. Acta Psychiatrica Scandinavia. 1989; 88: Suppl 353.

[12] Burlingame G, MacKenzie R, Strauss B. Small group treatment: evidence for effectiveness and mechanisms of change. In: Lambert M, editor. Bergin and Garfield's Handbook of psychotherapy and behavior change. New York: Wiley; 2004. pp. 648-696.

[13] Zimmermann P, Willmund G, Kröger N, Sestak A, Ströhle A. Stationäre Kurzgruppenpsychotherapie bei Bundeswehrsoldaten - Langzeitverlauf und Prädiktoren des Therapieerfolgs (Inpatient short-term group psychotherapie in Bundeswehr soldiers - long-term course and predictors of change). Wehrmed Monatsschr. 2010; 54(2): 35-38.

[14] Jones N, Fear NT, Greenberg N, Hull L, Wessely S. Occupational outcomes in soldiers hospitalized with mental health problems. Occup Med. 2009; 59(7): 459-465.

[15] King DW, King LA, Foy DW, Keane TM, Fairbank JA. Posttraumatic stress disorder in a national sample of female and male vietnam veterans: risk factors, war-zone stressors, and resilience-recovery variables. J Abnorm Psychol. 1999; 108: 164-170.

[16] Bundesministerium der Verteidigung (German Armed Forces Ministry of Defence). Medizinisch-psychologisches Stresskonzept der Bundeswehr (Medical psychological stress concept of the Bundeswehr). Bonn: BMVg-Verlag; 2004.
[17] Adler AB, Bliese PD, McGurk DM, Hoge CW, Castro CA. Battlemind debriefing and battlemind training as early interventions with soldiers returning from Iraq: randomization by platoon. J Consult Clin Psychol. 2009; 77(5): 928-940.

[18] Cornum R, Matthews MD, Seligman MEP. Comprehensive Soldier Fitness: building resilience in a challenging institutional context. Am Psychol. 2011; 66(1): 4-9.

[19] Frappell-Cooke W, Gulina M, Greene K, Hacker Hughes J, Greenberg N. Does trauma risk management reduce psychological distress in deployed troups? Occupational Med. 2010; 60(8): 645-650

[20] Gerardi SM. Part I. Work hardening for warriors: Occupational therapy for combat stress casualties. Work. 1999; 13(3): 185-195.

[21] Krüssmann K, Butollo R. Abschlussbericht für das Forschungsprojekt Untersuchung des langfristigen Adaptionsprozesses nach unterschiedlichen Nachsorgemaßnahmen im Kontext von Katastrophen und extrem belastenden Einsätzen (Research report long-term adaption processes due to secondary prevention after stressful at work). Bonn: BMI-Verlag; 2009.

[22] Corbière M, Shen J, Rouleau M, Dewa CS. A systematic review of preventive interventions regarding mental health issues in organizations. Work. 2009; 33(1): 81-116. doi: 10.3233/WOR-2009-0846. 